\title{
Science Students' Acceptance to use LINE Application in Laboratory Subject
}

\author{
J. Chutrtong and W. Chutrtong
}

\begin{abstract}
This phenomenological study aimed to determine if it could be used for academic purposes. In this study, we examined how undergraduate students accepted LINE for classroom-related activities and explored the factors that might affect their intention to use it. Data were collected from 47 undergraduate students of Suan Sunandha Rajabhat University. Data were collected by using a questionnaire and analyzed to see if relationships existed among factors when LINE was used to organize classroom experiences. The findings showed that students have good experience on LINE using. The perceived ease of LINE using, the attitude towards usage and the intention to use LINE were rated above 4.0 (from 5.0). The study also suggested some kinds of LINE-based learning activities preferred by students. Students preferred to use LINE for reading the story posted by the teacher $(89.4 \%)$, followed by communicating with teacher and classmates $(80.8 \%)$. Moreover, students like to send work (Informal) via line (76.6 \%). Expressing emotions by sending stickers is another element that students like $(\mathbf{7 4 . 5} \%)$. The least popular usage is calling through LINE (12.76 \%).
\end{abstract}

Index Terms-Acceptance, LINE application, Laboratory.

\section{INTRODUCTION}

Communication is a process that occurs continuously and constantly changes. It is a necessity for living together in human society as a medium that use to communicate to exchange feelings and ideas. Communication is also important factor in transfer-ring knowledge, technology, art and culture of humanity from the era to next generation. Today's communication has entered the digital technology era which make people life more convenient. The gap in communication between messenger and receiver is smaller. People are able to communicate easily with the form of technology that is always available to users, such as smart phones and applications on smartphones. Message conversation (Chat) on applications that developed simultaneously allow users to have more communication channels than only telephone conversations. There are many types of chat applications available. Facebook was considered the most popular and widely used applications. Another application that is gaining popularity is LINE, which created in mid of 2010.

LINE was first developed in 2010 in Japan by the cooperation of NHN Japan, a company that provides internet

Manuscript received August 13, 2019; revised January 5, 2020.

Jaruwan Chutrtong is with Industrail Microbiology, Faculty of Science and Technology, Suan Sunandha Rajabhat University, Bangkok, Thailand (e-mail: jaruwan.ch@ssru.ac.th).

Waradoon Chutrtong was with Chemistry, Faculty of Science, Srinakarinwirot University, Bangkok, Thailand (e-mail: waradoon@swu.ac.th). games and search engine systems, with Naver Japan Corporation and Livedoor. The word LINE occurred after Japan had a major earthquake in the country in 2011, named Tohoku Earthquake. That incident caused paralyzation communication systems in Japan. People used public telephone service that is automatically installed to be able to use when an unexpected disaster occurs. Many people had to line up to wait for service. This is the origin of the word LINE [1].

LINE is an application for chatting on various communication devices such as smartphones, computers and tablets. Users can communicate by typing messages from one communication device to another. LINE has developed to have a variety of capabilities to support multiple applications. The highlight that makes LINE different from other chat applications is stickers which showing basic feelings. In addition to LINE providing Instant Messaging services similar to WhatsApp and MSN applications, LINE also offers free voice call service which is able to call over $4 \mathrm{G}$, EDGE, Wi-Fi network without having to pay any extra fees. LINE is an application that combines the capabilities of WhatsApp and Wi-Fi in one. LINE has also added Timeline feature that is similar to Facebook's Timeline. User can share information and update various situations through posting pictures and setting status. These make line an application that has full functionality, respond to the lifestyle of the new generation completely [2]. Therefore, it is not surprising that LINE is populist application. Although LINE is a new application in the smartphone industry but it hit the market, especially in Asia. In 2014, LINE revealed that there are over 400 million users worldwide with a growth rate of $33 \%$. In 2017, LINE is the most widely used social media application in Thailand. LINE users in Thailand are second in the world after Japan [3]. The development of LINE use become increasingly pervasive in every educational level of students too.

In addition, information and communication technologies (ICTs) have a great impact on the process of students' participation in a course [4]. Technology can enhance communication in ways that challenge and destroy barriers of time and distance that teachers and students often face. Apart from other course management systems, informal systems such as LINE applications seem to play role in the teaching and learning processes. Although these social networks are usually used for social interaction, they can also be used as communication channels for academic purposes. They enable teacher and learners to cooperate with each other easily [5]. Despite the known benefits of student participation, student-teacher meeting can be stressful for students. More engaging with peers and teachers increases their learning 
efficacy [6]. It gives an immediate connection, if online all the time. Moreover, stickers and emoticons also create a friendly relationship between teachers and students [7]. Some emoticons are used to strengthen the message while others represent tone of voice such as surprise, anger, disappointment and sadness. Students and teacher can use these to express their own feelings without being threatened [8]. Teachers interact with students by using emoticons and stickers will help to break down generation gaps.

From such importance, the researcher is interested in studying the application behavior of the LINE application, the satisfaction and the use of the student's needs, which has already been communicated in daily life and has smartphone that is convenient to use. This Research believes that teacher-student communication fosters better understanding and collaboration to make education a wholesome experience for learner.

\section{RESEARCH METHODOLOGIES}

To develop this project, the selection technological tools (LINE) for student- teacher communication must be considered:

1) The nature of the message. It should not be a message specific to a particular student or private communication.

2) Types of technology that both teachers and student have access.

3) Skills and willingness of student and teachers to use the technology.

4) Scope of use, replace face-to-face communication or complement offline communication.

The participants were the second and third year students of Industry microbiology who enrolled in bachelor's degree level course titled, food microbiology and quality control at Suan Sunandha Rajabhat University in Thailand during the first semester in 2017. They were 3-credit, 15-week course. During the semester, activities using LINE, such as discussing on the provided topic and giving response to any questions, were created. LINE was used instead of the Learning Management System to connect with students, so students needed to follow up the course contents or announcements through LINE.

The instrument of this study was a questionnaire which had three sections. The first section was data of age, gender, Internet access on mobile phone and kinds of social networks they were using. The second section consisted of items that measured perceived ease of use, attitude towards usage and intention to use LINE. Five-point scale was used with the following categories: 5 = strongly agree; 4 = agree; $3=$ undecided; 2 = disagree; and 1 = strongly disagree. The last section provided two open-ended questions. The participants specified what they viewed as the main benefits and drawbacks of LINE usage.

Data were statistically recorded and analyzed by SPSS/Windows program. The first section were calculated for frequency and percentage. The second section were analyzed quantitatively for means and standard deviations.

\section{RESEARCH FINDINGS}

\section{A. The First Section Data}

It was data about age, gender, Internet access on mobile phone and kinds of social networks they were using as showed in Table 1. Among the 47 students, $100 \%$ were $20-23$ years old $85.10 \%$ were female and $14.9 \%$ were male. The theme of Internet access was also explored. 100\% owned a mobile phone and all of them had a notebook which can access the Internet. About the kinds of social networks they were using, LINE was chosen the most (100\%), followed by Twitter (87.2\%), Facebook (85.1\%), Instagram (63.8\%) and Youtube $(25.5 \%)$. Moreover, the results indicated that the tools that students need to use to contact teacher is LINE $(95.7 \%)$, followed by messenger on Facebook (74.5\%) and e-mail $(31.9 \%)$.

TABLE I: GENERAL INFORMATION OF STUDENTS

\begin{tabular}{lcc}
\hline \multicolumn{1}{c}{ Information } & number & percentage \\
\hline Sex & 7 & 14.9 \\
- -Male & 40 & 85.1 \\
- Female & & \\
Age & 12 & 25.5 \\
- 20 year old & 15 & 31.9 \\
- 21 year old & 17 & 36.2 \\
- 22 year old & 5 & 10.6 \\
-23 year old & & \\
Kinds of social networks using & 47 & 100 \\
- LINE & 41 & 87.2 \\
- Twitter & 40 & 85.1 \\
- Facebook & 30 & 63.8 \\
- Instagram & 12 & 25.5 \\
- Youtube & & \\
\hline
\end{tabular}

\section{B. The Second Section Data}

It was data concern attitude of students towards LINE usage for academic purposes, intention to use LINE, perceived ease of LINE use and perceived usefulness of LINE in their study. The statistics of the three constructs are shown in Table 2. All items were rated at high levels since they were above 4.0, and the standard deviations ranged from 0.65 and 0.83 . Items of this section include:

1) Perceived ease of LINE using

- send video or picture

- watch video or see picture

- save video or picture

- send sticker or emoticon

- send message

- calling

2) Attitude towards usage

- make learning easier

- feel good for academic purpose

- provide enjoyment

3) Intention to use LINE

- intend to use in this course

- intend to use in all course of this semester

- intend to use in the future

Students gave information about the uses and preferences on LINE-based activities as showed in Table 3. Students preferred to use LINE for reading the story which posted by teacher $(89.4 \%)$, followed by communicating with teacher and classmates $(80.8 \%)$, send work $(76.6 \%)$, express 
emotions by sending stickers $(74.5 \%)$ and making a call through LINE to talk with teacher $(12.76 \%)$.

TABLE II: MEAN AND STANDARD DEVIATION OF FACTORS

\begin{tabular}{lcc}
\hline \multicolumn{1}{c}{ Factor } & mean & S.D. \\
\hline Perceived ease of LINE using & & \\
- send video or picture & 4.12 & 0.83 \\
- watch video or see picture & & \\
- save video or picture & & \\
- send sticker or emoticon & & \\
- send message & 4.38 & \\
Attitude towards usage of LINE & & \\
- make learning easier & & \\
- feel good for academic purpose & \\
- provide enjoyment & 4.48 \\
Intention to use LINE & \\
- intend to use in this course & \\
- intend to use in all course of this semester & \\
- intend to use in the future & \\
\hline
\end{tabular}

Students also commented the problem when use LINE for academic purposes:

1) It was not convenient for sending long video clips.

2) Not able to access internet made missing information.

3) Misunderstanding of the message

TABLE III: ITEM WHICH STUDENTS PREFERRED TO USE LINE

\begin{tabular}{lc}
\multicolumn{1}{c}{ TABLE III: ITEM WHICH STUDENTS PREFERRED TO USE LINE } \\
\hline
\end{tabular}

\section{The Last Section Data}
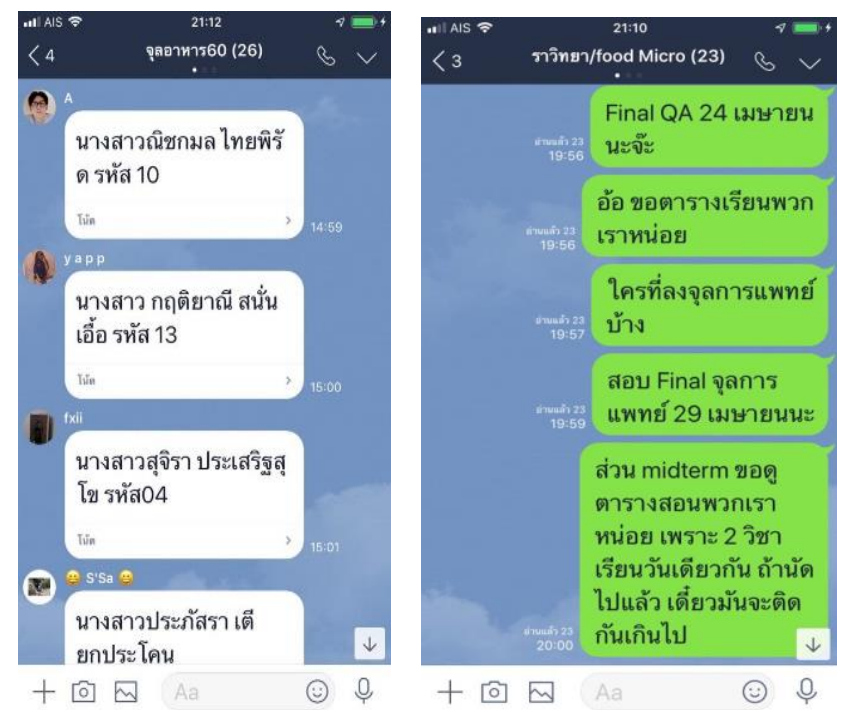

Fig. 1. Teacher-student communication.

The last section of questionnaire asked participant to comments to two open-ended questions on the LINE usage for academic purposes. Most of their reply was the convenience in connecting with member in the course. It is fast and easy. They only sent the message to the group. More than that, they could create a small working group when they had an assignment to do out-of-class. They could consult teacher anytime. LINE helped them save time and, also, money. Calling through LINE, even free of charge, may be limited. It is not as effective as using a phone call. In some areas (in Thailand), the internet signal may not work well. Therefore, using calls through LINE is not the usually way that people use, including students.

Fig. 1 show the messages of students and teacher sent in LINE. The content of messages are variety. Students can ask for details of works. Appointments also can be done.
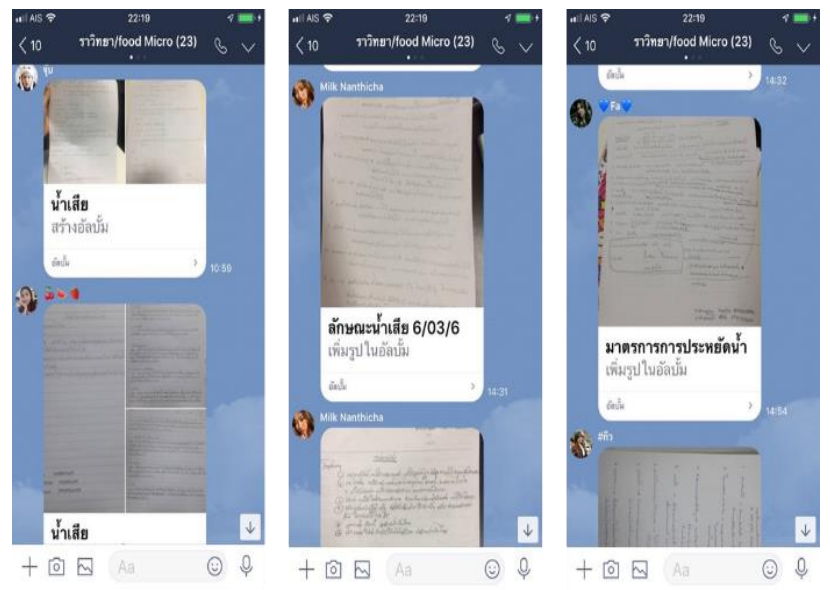

Fig. 2. Send assign work.

Fig. 2 is sending works via LINE. Submitting the works in this way is just to check that the student has completed the work within the specified time. It is convenient for teacher when unable to check the submission at or during that time. Sometime teachers may have the necessary missions to perform. Delivering work on schedule is a practice for students. They must know their duties and try to do best.

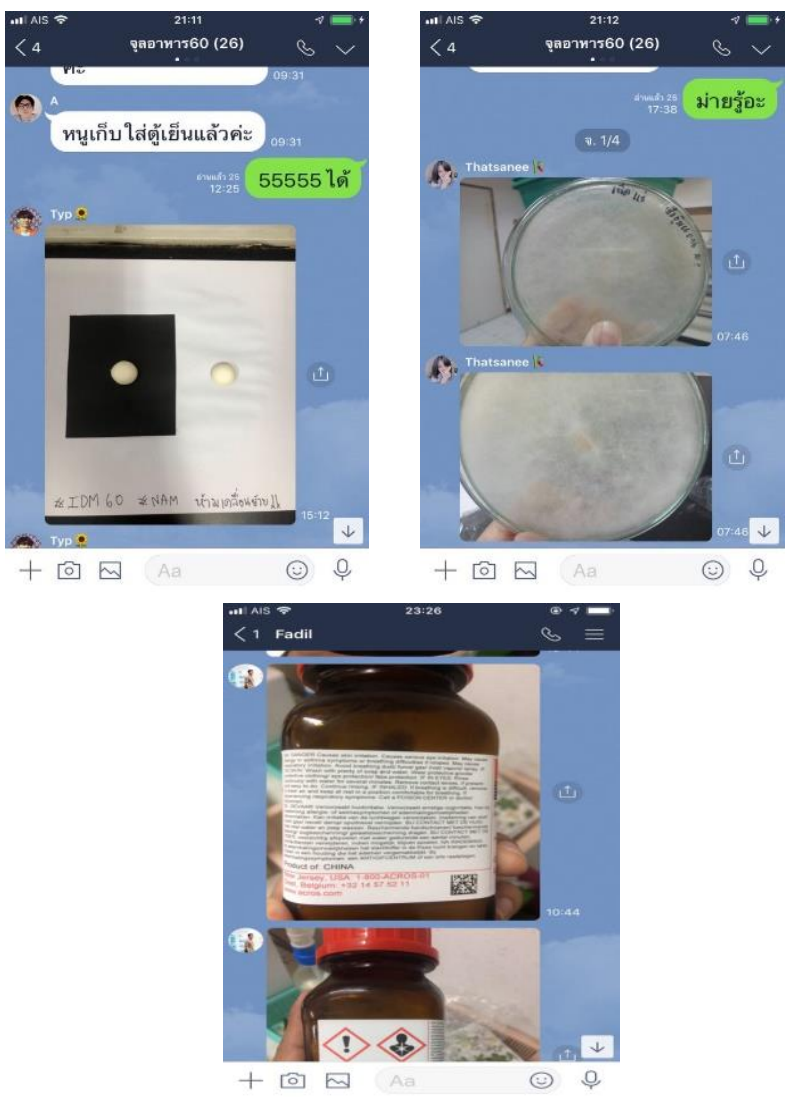

Fig. 3. Laboratory consulting.

Fig. 3 shows the message that students consult teacher 
about the experimental results. Consultation about the results of the experiment that students have to check by themselves outside of class hours can be convenient. It can be real time interaction if teacher is using this application. Immediate consultation can reduce errors or fix errors that occur.
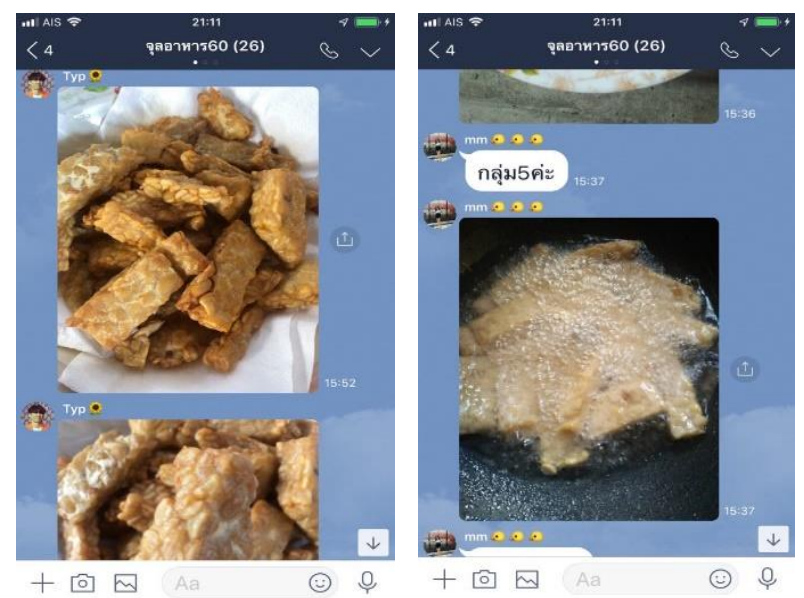

Fig. 4. Report experiment result (after class time).

Fig. 4 is photographs that students send the results to teacher via LINE. Some experimental results may be different if leave it for long time. Therefore, sending pictures as soon as the experiment finish made better judge of the student works because teacher can see the actual results of the experiment. Even though teacher doesn't see the real thing but the photos from modern mobile phone are good quality. The image are looks like the real thing. This convenient reporting results in better learning of practical subjects, such as laboratory subject.
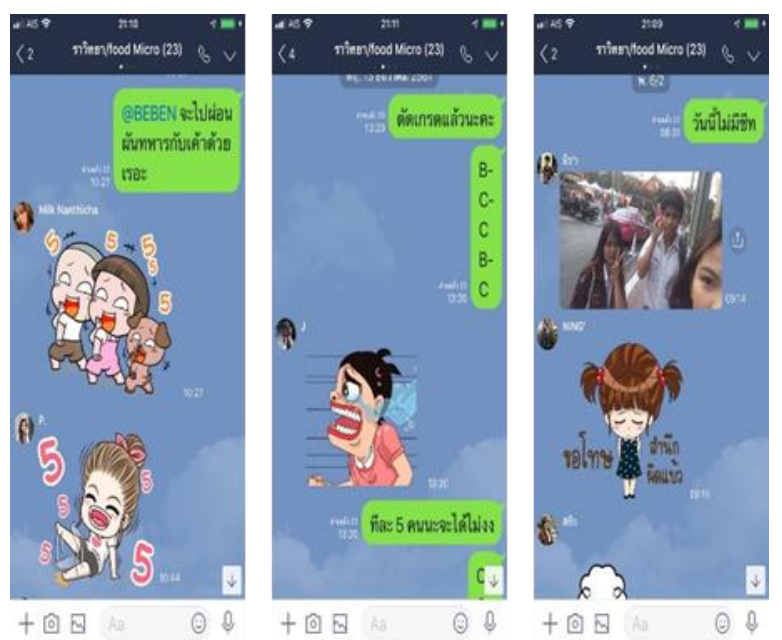

Fig 5. Sending picture and stickers to express feelings.

Fig. 5 is sending sticker which is a line tool. In addition, pictures of students are also sent. Using stickers or pictures is easier to express feelings than using words and it also reduce stress situations. The interaction between teacher and students by sending stickers makes close relationship which is good for teaching and learning. Normally, Thai students rarely ask questions because they are embarrassed and afraid of instructors. When students are intimate with the teacher, they will be assertive. They will dare to ask more questions.

But not every topic can communicate or understand through LINE. Sometime it has some limitations. Images of very small or have many details things such as color or organelle of microorganism are difficult to differentiate, as in Fig. 6.

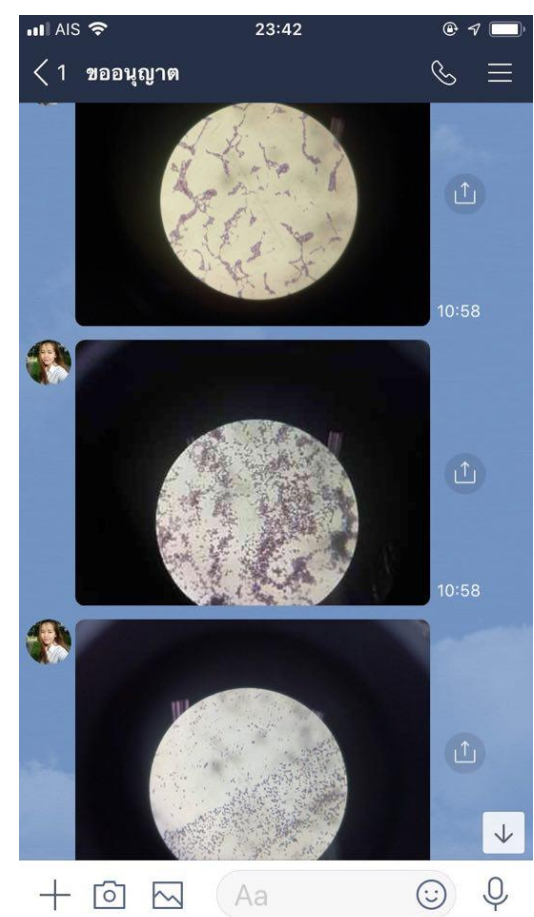

Fig. 6. Examples of images that are difficult to observe.

\section{DISCUSSION}

Social media is now a part of life. Many organizations have had movements through those media such as Twitter and Facebook. In this study, we found that almost every student owned a smartphone or a tablet. From our study, the LINE application was one of the common methods used by students to communicate between themselves and their acquaintance. This study found that the students had a positive attitude on using LINE since it was convenient for communication. This study also demonstrated that an instant messaging application was not only useful for work but also useful for academic discussion. It is the use of instant messaging communication in class. Using this application also promoted communication and expanded the student comfort zone. LINE seems to be a useful tool in consultation and education aspects since it is convenient and offers two-way communication.

\section{Conclusion}

From the results, the intention to use LINE as a tool for class management can be motivated by presenting usefulness of the technology. Teacher must recognize the potential of LINE for effective interaction of student and teacher. It is also important that students have a positive attitude and feel good with LINE usage. The interaction provided by LINE between teacher and student practically reinforces student learning.

In education part, not only LINE that can use for class management but also Facebook, Twitter and other social application can extend the interactive experience of the classroom [9]. Students in this era are already living with social media. Using social media with teaching and learning 
will make students familiar and not be bored. There must be adjustment of teaching methods and attitudes for students in order to accept the experience of using these technological tools. Social media applications should be able to be used in variety of subjects, even laboratory subjects [10]. But the use of medium also have the disadvantages. It can cause misunderstandings. Teaching in the classroom makes interacts in the presence of teachers and students. The encounter will make it better to understand the feelings of others. So, teacher should use it by combining with the traditional classroom teaching methodologies, which will be an appropriate way to use social media to increase student learning efficiency.

\section{CONFLICT OF INTEREST}

"The authors declare no conflict of interest".

\section{AUTHOR CONTRIBUTIONS}

Jaruwan conducted the research, analyzed the data; and Waradoon search the previous research and wrote the paper. We approved the final version.

\section{ACKNOWLEDGMENT}

This study was successful by financial support from Suan Sunandha Rajabhat University and many helps from my colleagues.

\section{REFERENCES}

[1] W. Frawley, G. Piatetsky-Shapiro, and C. Matheus, "Knowledge discovery in databases: An overview," AI Magazine, Fall, pp. 213-228, 1992.

[2] E. Bones, P. E. Hasvold, E. Henriksen, and T. Strandenaes, "Risk analysis of information security in a mobile instant messaging and presence system for healthcare," Int. J Med Inform, vol. 76, pp. 677-687, 2007.

[3] A. Ketchan, N. Lungyoo, and S. Makka, "Research report of the Impacts of the line application utilization on elderly lifestyle in Bangpakong sub-district, Chachoengsao province," Rajapark Journal, vol. 12 , pp. 52-65, 2018.

[4] C. Chang, C. Yan, and J. Tseng, "Perceived convenience in an extended technology acceptance model: Mobile technology and English learning for college students," Australasian Journal of Educational Technology, vol. 28, no. 5, pp. 809-826, 2012.

[5] S. Gabarre and C. Gabarre, "Using mobile Facebook as an LMS: Exploring impeding factors," Gema Online Journal of Language Studies, vol. 13, no. 3, pp. 99-115, 2013.

[6] J. Chutrtong, "Activity beyond classroom enhance understanding of science," Economic and Social Development: Book of Proceedings; Varazdin, pp. 412-416, 2016.

[7] H. Thiry and S. L. Laursen, "The role of student-advisor interactions in apprenticing undergraduate researchers into a scientific community of practice," J Sci Educ Technol, vol. 20, pp. 771-784, 2001.

[8] D. Gonzalez, "Teaching and learning through chat: A taxonomy of educational chat for EFL/ESL," Teaching English with Technology, vol. 3, no. 4, pp. 57-69, 2003

[9] A. R. Lauricella, C. K. Blackwell, and E. Wartella, The "new" technology environment: The role of content and context on learning and development from mobile media," Media Exposure during Infancy and Early Childhood, pp. 1-23.

[10] E. Vázquez-Cano, "Mobile distance learning with smartphones and apps in higher education," Educational Sciences: Theory and Practice, vol. 14 , pp. 1505-1520, 2014.

Copyright $\odot 2020$ by the authors. This is an open access article distributed under the Creative Commons Attribution License which permits unrestricted use, distribution, and reproduction in any medium, provided the original work is properly cited (CC BY 4.0).

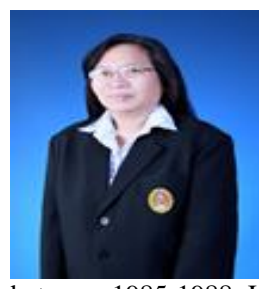

Jaruwan Chutrtong was born in Bangkok, Thailand. She got the bachelor of science (B.Sc.) in biology (microbiology) from Srinakharinwirot University, Bangkok Thailand in 1985; the master of science (M.Sc.) in microbiology from Kasetsart University, Bangkok Thailand in 1994.

She worked as medical scientist in Regional Medical Sciences Center in Nakhon Ratchasima between 1985-1988. In 1988-1994, she worked as MEDICAL SCIENTIST in Department of Medical Sciences, Ministry of Public Health in Bangkok. After that, from 1994 - now, she is LECTURER in industrial microbiology department, faculty of science and technology Suan Sunandha Rajabhat University, Bangkok Thailand. Previous publications:

1. J. Chutrtong, "Acceptance of Consumer on Various Tempeh and Protein Content Comparison," International Journal of Biological, Life Science and Engineering, vol.7, pp. 5-8, 2013.

2. J. Chutrtong, "Preparation of Tempeh Spore Powder by Freeze Drying," World Academy of Science, Engineering and Technology International Journal of Biological, Veterinary, Agricultural and Food Engineering, vol.8, 2014.

3. J. Chutrtong, "The Dynamics of Microorganisms in Dried Yogurt Storages at Different Temperatures," Journal of Biological, Biomolecular, Agricultural, Food and Biotechnological Engineering, vol.8, No.5, pp. 459-461, 2014.

4. J. Chutrtong, "Comparison of Corncob and Corn Using as Fungal Culture Medium," Procedia-Social and Behavioral Sciences, vol.197, pp. 797-800, 2015 .

5. J. Chutrtong, "Survival of Probiotic Bacteria in Freeze-Dry Yogurt Starter Cultures Storage at 4 and 30 Degree Celsius," Procedia-Social and Behavioral Sciences, vol.191, pp. 2219-2225, 2015.

6. J. Chutrtong, "Activity beyond classroom enhance understaning of science," Economic and Social Development: Book of Proceedings, pp. 412-415, 2016

7. J. Chutrtong, W. Chutrtong and N. Boonman, "Composition of Neurospora crassa Mycelium Color," International Journal of Bioscience, Biochemistry and Bioinformatics, vol. 8, no. 4, pp. 237-244, 2018.

8. J. Chutrtong and W. Chutrtong, "Achievement of Sanitary Learning by Problem-Based Learning (PBL)" International Conference on Applied Human Factors and Ergonomics, pp. 423-429, 2018.

9. J. Chutrtong and W. Chutrtong, "Paper for Chromatographic Technique from Coconut Pulp Cellulose," Procedia Manufacturing, vol. 32, pp. 969-974, 2019.

10. J. Chutrtong and W. Chutrtong, "Simple Method for Monitoring Melamine in Food by Ion Pair Chromatography," Procedia Manufacturing, vol. 32, pp. 1000-1007, 2019.

11. J. Chutrtong and K. Kularbphettong, "Study on optimal conditions of lemongrass extraction,” E3S Web of Conferences, vol. 100, pp. 8, 2019.

Study on optimal conditions of lemongrass extraction

Asst. Prof. Jaruwan Chutrtong: memberships - committee of Educational Professional Foundation.

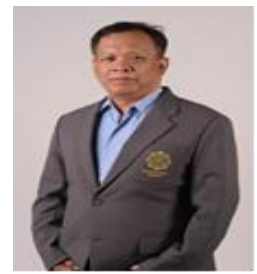

Waradoon Chutrtong was born in Bangkok, Thailand. He got the bachelor of science (B.Sc.) in chemistry from Ramkhamheng University, Bangkok Thailand in 1984; the master of Science (M.Sc.) in chemistry (analytical) from Kasetsart University, Bangkok Thailand in 1995.

He worked as medical scientist in Regional Medical Sciences Center in Nakhon Ratchasima between 1986-1989. In 1989-1995, he worked as medical scientist in the Department of Medical Sciences, Ministry of Public Health in Bangkok. After that, from 1995 - now, he is LECTURER in chemistry department, faculty of science, Srinakharinwirot university, Bangkok Thailand. Previous publications:

1. J. Chutrtong, W. Chutrtong and N. Boonman, "Composition of Neurospora crassa Mycelium Color," International Journal of Bioscience, Biochemistry and Bioinformatics, vol. 8, no. 4, pp. 237-244, 2018.

2. J. Chutrtong and W. Chutrtong, "Achievement of Sanitary Learning by Problem-Based Learning (PBL)" International Conference on Applied Human Factors and Ergonomics, pp. 423-429, 2018.

3. J. Chutrtong and W. Chutrtong, "Paper for Chromatographic Technique from Coconut Pulp Cellulose," Procedia Manufacturing, vol. 32, pp. 969-974, 2019.

4. J. Chutrtong and W. Chutrtong, "Simple Method for Monitoring Melamine in Food by Ion Pair Chromatography," Procedia Manufacturing, vol. 32, pp. 1000-1007, 2019.

Asst. Prof. Waradoon Chutrtong: memberships - committee of Council of science and technology professionals. 